\title{
DETERMINATION OF THE OPTIMUM PRELOAD OF ROLLER BEARINGS IN TERMS OF THEIR LIFE USING FEM
}

The objective of this paper is to describe the procedure of correct determination of the optimum preload of tapered roller bearings in terms of their fatigue life, using the procedure laid down in ISO 281, and by analysis of contact stress state (analytically and by the FEM) with application of the Lundberg-Palmgren theory. The procedures will be applied to a specific example of the fit of the output shaft of a gearbox in a pair of tapered roller bearings designed specifically for this application.

Keywords: Preload, tapered roller bearings, radial load distribution, fatigue life, Lundberg - Palmgren, FEM.

\section{Introduction}

Roller bearings are one of the basic structural components of machines, used to fit the rotating parts in frames or housings. They capture and transmit reaction forces from external loading. Typical applications of rolling bearings are fits of shafts in gearboxes and transmissions. However, there are also special fits where the shaft is fitted in tapered roller or ball angular contact bearings, and proper preload must be determined to ensure their proper function [1 and 2]. The proper preload inferred between a pair of tapered roller or ball bearings with angular contact has a great impact on the service life of both the bearings forming the fit [3]. Improperly determined preload can significantly reduce their life or even damage the whole transmission. Figure 1 shows a typical shaft fit in two tapered roller bearings in the "O" configuration [4 and 5].

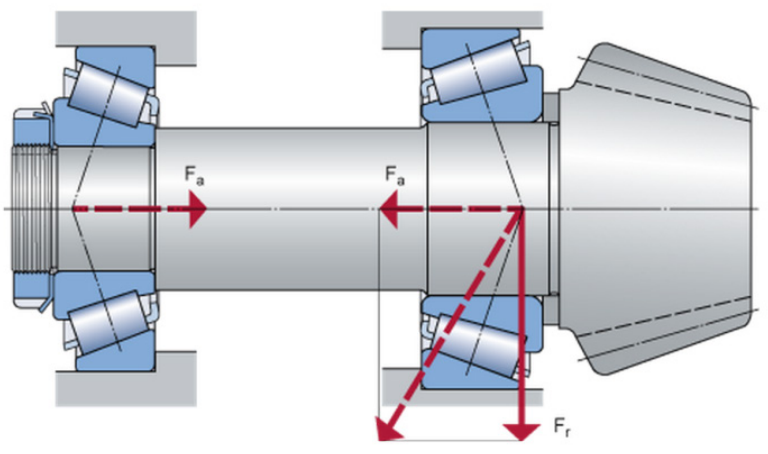

Fig. 1 Typical shaft fit in a pair of tapered roller bearings
Proposal of proper preload and its impact on bearing life will be shown using the example of the output shaft fit deposit in an 8-speed gearbox in a pair of tapered roller bearings in the "O" configuration. The gearbox output shaft is fitted, due to dimensions, in atypical single-row tapered roller bearings 32008 with the basic parameters as follows: $C_{r}=79.784 \mathrm{kN}$, $e=0.318, Y=1.881$, the inner ring diameter $\mathrm{d}=40 \mathrm{~mm}$, the outer ring diameter $\mathrm{D}=80 \mathrm{~mm}$, the bearing width (broadness) $\mathrm{B}=21.8 \mathrm{~mm}$, nominal contact angle $\alpha=12^{\circ}$, with the number of rolling elements $Z=17$ and effective length $L_{\text {we }}=14.3 \mathrm{~mm}$. The rolling element profile geometry consists of an unmodified logarithmic profile. Figure 2 shows a scheme of the 8 -speed gearbox, the output shaft is fit in bearings marked A5 a B5.

The aim was to design the proper fit of the output shaft and determine optimal bearing preload for the gearbox working cycle specified in Table 1.

\section{Calculation of equivalent dynamic load on the gearbox output shaft bearings}

The load acting on rolling bearings constituting the fit of the output shaft is based on the forces acting on the gearwheel at the end of the shaft, as shown in Fig. 3 [6]. At the end of the shaft, gearwheel is used with straight teeth in order to show more clearly the difference in the preload influence on the life calculated through equivalent dynamic load. The same is true for gears with a small angle of teeth inclination $\beta$.

\footnotetext{
* Slavomir Hrcek, Robert Kohar, Stefan Medvecky, Branislav Krchnavy, Marcel Caco Faculty of Mechanical Engineering, University of Zilina, Slovakia E-mail: slavomir.hrcek@fstroj.uniza.sk
} 


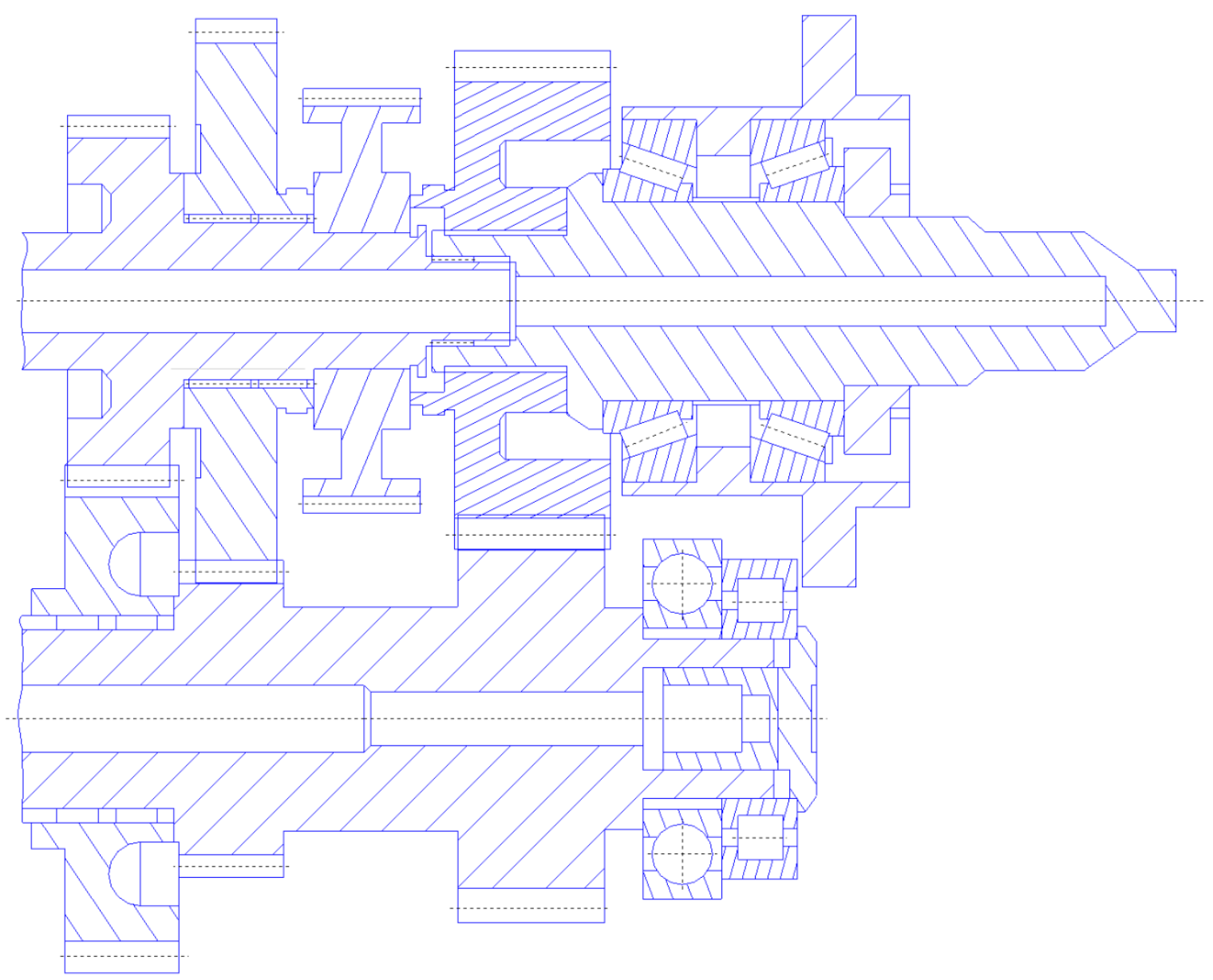

Fig. 2 Scheme of the 8-speed gearbox

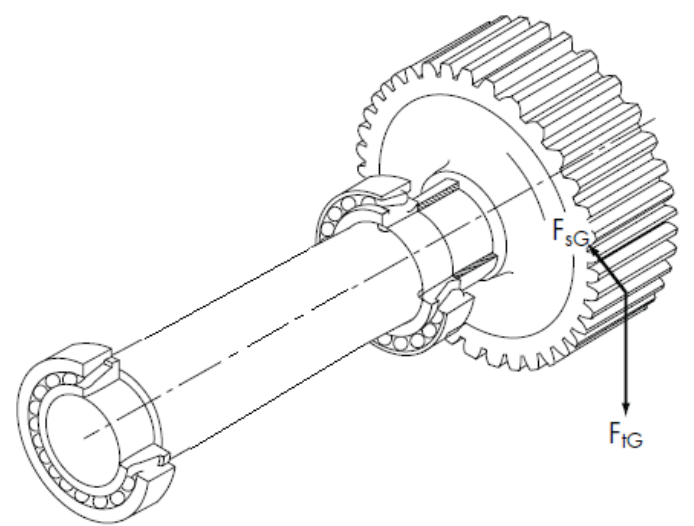

Fig. 3 Output shaft fit
Force $F_{t G}$ is the tangential component of forces from the gears, force $F_{s G}$ is the radial component of forces from the gears and this component is transmitted by rolling bearings.

From the load by the teeth, and using moment equilibrium, we calculated the response per bearings in "O" configuration, where the distance of the force acting to the bearing $\mathrm{A}$ is $\mathrm{a}=17.67$ $\mathrm{mm}$, and the effective bearing spread between the bearings $A$ and $\mathrm{B}$ is $\mathrm{b}=53.5 \mathrm{~mm}$. Sizes of response for each working cycle are shown in Table 1.

Equivalent load for tapered roller bearings according to ISO 281 [7] is calculated using the following equations:

$\mathrm{P}_{\mathrm{e}}=\mathrm{F}_{\mathrm{r}}$

$$
\text { for } F_{a} / F_{r} \leq e
$$

$\mathrm{P}_{\mathrm{e}}=0.4 \mathrm{~F}_{\mathrm{r}}+\mathrm{YF}_{a}$ for $\mathrm{F}_{\mathrm{a}} / \mathrm{F}_{\mathrm{r}}>\mathrm{e}$ where $\mathrm{e}$ is the limit value of the ratio of the axial to the radial load, $\mathrm{Y}$ is the coefficient of dynamic axial load. Since the output shaft 
fit consists of a pair of identical tapered roller bearings, we will further consider only the more loaded bearing $\mathrm{A}$, which is closer to the gearwheel.

Working cycle and response forces in bearings

Table 1

\begin{tabular}{|c|c|c|c|c|c|}
\hline Gear & Torque & $\mathrm{F}_{\mathrm{sG}}$ & Rarad & RBrad & Time \\
\hline \# & $\mathrm{Nm}$ & $\mathrm{N}$ & $\mathrm{N}$ & $\mathrm{N}$ & hours \\
\hline 1 & 500 & 42521.6 & 56565.7 & 14044.1 & 0.44 \\
\hline 2 & 700 & 35865.4 & 47711.0 & 11845.6 & 5.96 \\
\hline 3 & 700 & 24816.6 & 33013.0 & 8196.4 & 12 \\
\hline 4 & 700 & 18807.1 & 25018.7 & 6211.6 & 12.08 \\
\hline 6 & 700 & 11493.0 & 15289.0 & 3795.9 & 20.21 \\
\hline 7 & 700 & 9618.2 & 12794.9 & 3176.7 & 14.22 \\
\hline 8 & 700 & 8294.3 & 11033.8 & 2739.5 & 14.22 \\
\hline & & & & & 79.13 \\
\hline
\end{tabular}

Table 2 shows the calculation of equivalent load according to IS0 281 based on the external radial and axial dynamic loads. The individual preload values correspond to the levels of the axial load, then the center of the table presents in a matrix form the above-mentioned values of partial equivalent loads $\mathrm{P}_{1}, \mathrm{P}_{2}$, etc., calculated by the ratio of the radial and axial loads from equations 1 and 2. Subsequently, we calculated the resultant equivalent load $\mathrm{P}_{\mathrm{e}}$ for a working cycle according to equation 3 for each preload value.

Since the gearbox operates in different modes, it is necessary to calculate the resultant equivalent load at the same revolutions (gearbox operates at the speed of $5000 \mathrm{rpm}$ at all stages of the working cycle), using the following equation:

$$
\mathrm{P}_{\mathrm{e}}=\sqrt[n]{\mathrm{P}_{1}^{\mathrm{n}}\left(\frac{\mathrm{t}_{1}}{\sum \mathrm{t}_{\mathrm{i}}}\right)+\mathrm{P}_{2}^{\mathrm{n}}\left(\frac{\mathrm{t}_{2}}{\sum \mathrm{t}_{\mathrm{i}}}\right)+\cdots}
$$

Working cycle and equivalent load in the bearing A

Table 2

\begin{tabular}{|c|r|r|r|r|r|r|}
\hline Preload (mm) & 0 & 0.05 & 0.1 & 0.15 & 0.2 & 0.25 \\
\hline Rarad (Naa $(\mathrm{N})$ & 0.0 & 4506.8 & 9735.3 & 15275.9 & 21029.4 & 26946.7 \\
\hline 56565.7 & 56565.7 & 56565.7 & 56565.7 & 56565.7 & 62200.6 & 73335.9 \\
\hline 47711.0 & 47711.0 & 47711.0 & 47711.0 & 47831.4 & 58658.7 & 69794.1 \\
\hline 33013.0 & 33013.0 & 33013.0 & 33013.0 & 41952.2 & 52779.5 & 63914.9 \\
\hline 25018.7 & 25018.7 & 25018.7 & 28327.9 & 38754.4 & 49581.7 & 60717.1 \\
\hline 15289.0 & 15289.0 & 15289.0 & 24436.0 & 34862.6 & 45689.9 & 56825.3 \\
\hline 12794.9 & 12794.9 & 13599.2 & 23438.4 & 33864.9 & 44692.2 & 55827.6 \\
\hline 11033.8 & 11033.8 & 12894.7 & 22733.9 & 33160.5 & 43987.8 & 55123.2 \\
\hline \hline Pe (N) & 27359.5 & 27434.4 & 30121.4 & 37830.1 & 48441.5 & 59480.7 \\
\hline
\end{tabular}

\section{Calculation of optimal preload using FEM}

We used CAD system PTC/Creo to create a 3D model of the gearbox output shaft fit. Subsequently, the model was imported into the software environment ANSYS/Workbench, where static structural analysis was created for the needs of analysis to determine the optimal preload. The model networking used standard elements from Ansys software library, the volume networking used the SOLID185 element and the contact pairs of rolling elements - raceways used the CONTA174 and TARGE170 elements. The entire model contained 2,635,001 elements and 807,815 nodes. Contacts between the rolling elements and raceways were defined as frictional with the coefficient of Coulomb friction 0.1. Bearing rings fitting in the housing and on the shaft was defined by frictionless contact with the respective value of interference of the inner ring on the shaft. Since the model of fitting is symmetrical, we defined the plane of symmetry $x-y$ to simplify the calculation. Boundary conditions (Fig. 4) were defined at the face of the housing largest fit by removing degrees of freedom in the direction of the $\mathrm{x}$ and $\mathrm{y}$ axes, the radial load from the gearwheel on the output shaft was applied at the end fit of the shaft at the point of the gearwheel force in the y axis direction. Definition of preload was prescribed by displacement at the faces of the outer bearing rings uniformly against each other in the $\mathrm{x}$ axis direction.

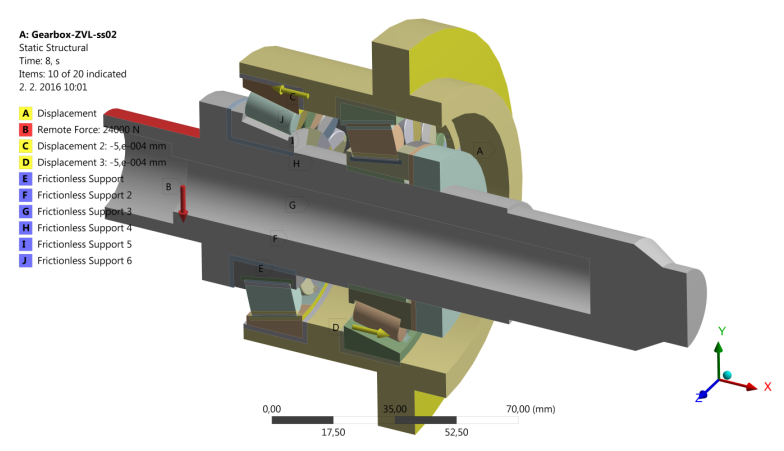

Fig. 4 Definition of boundary conditions and load

From the results of the static structural analysis, using the finite element method, we first conducted analysis of the load distribution on individual rolling elements depending on the size of the external load (force from the gearwheel) and on the size of preload between the pair of tapered roller bearings. Figure 5 shows the radial load distribution on the rolling elements at different preload values.

The analysis of the load indicates that the size of the forces acting between the rolling elements and the raceways depends on the size of preload at the same outer load, they are not constant and with increasing preload also increases the number of rolling elements that transfer this load. 

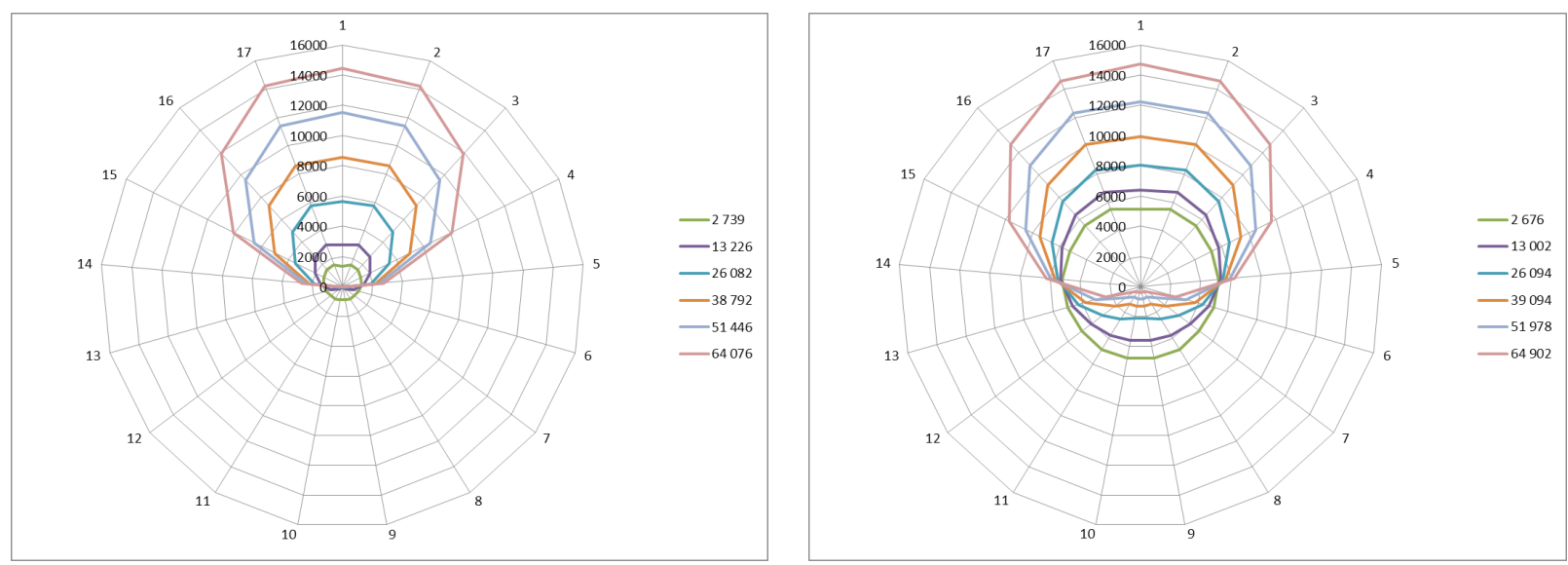

Fig. 5 Load distribution on the rolling elements depending on the size of the load, upper at $0.05 \mathrm{~mm}$ preload, lower at $0.25 \mathrm{~mm}$ preload
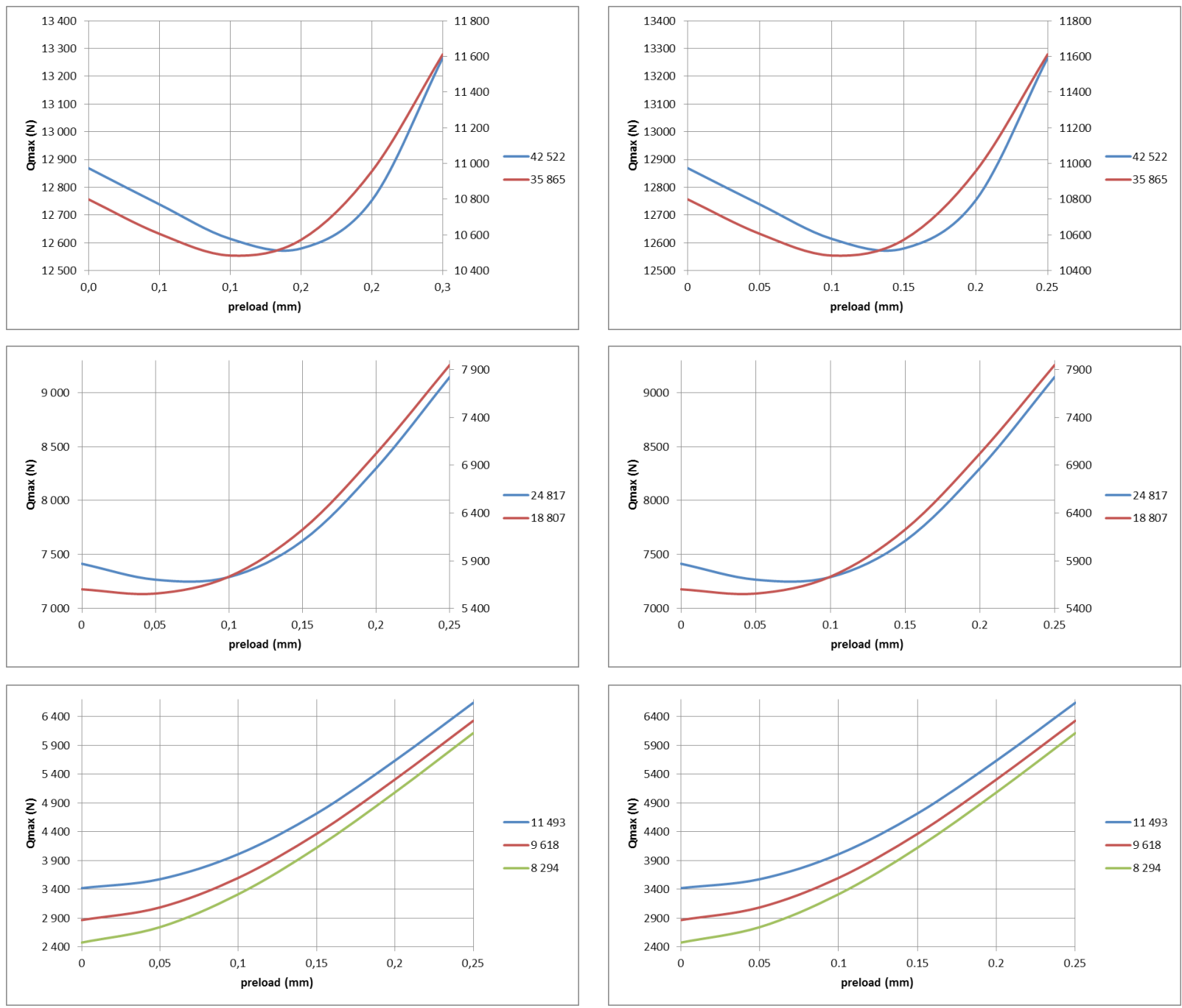

Fig. 6 Dependence of the maximum rolling element load on the size of preload at different sizes of outer load 
Figure 6 shows the dependence of the maximum rolling element load on the size of preload at different sizes of outer load. The size of preload plays an important role in particular at large outer radial load.

Figure 7 shows the dependence of the maximum rolling element load on the size of outer load at various preload values. The courses show that it is not a linear dependence between the maximum rolling element load and outer load and that the course depends on the preload size between the tapered roller bearings that make up the fit on the gearbox output shaft.

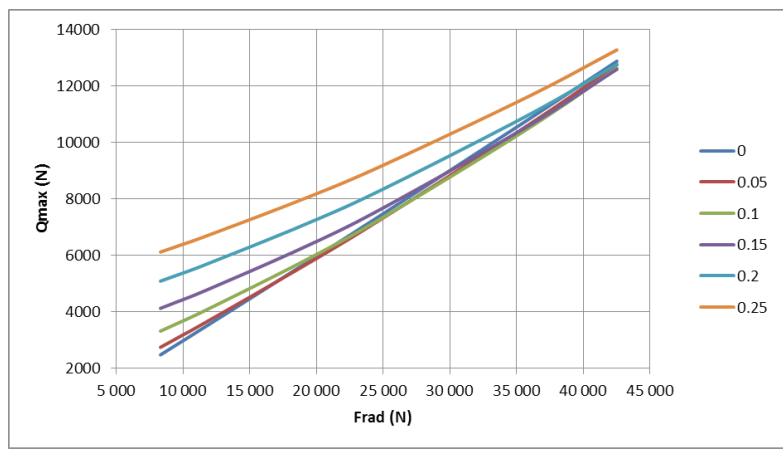

Fig. 7 Dependence of the maximum rolling element load on the size of outer load at various preload values

From the finite element analysis performed on the model of the output shaft fit, we analyzed the maximum orthogonal shear stress $\tau_{\mathrm{yz}}$, the depth $\mathrm{z}_{0}$ at which this stress acts and at what length $l_{\text {ef }}$ depending on the size of force of the maximum rolling element load $\mathrm{Q}_{\max }$. Calculation of service life of the inner ring of a tapered roller bearing 32008 according to the Lundberg-Palmgren theory [8 and 9], based on the calculation using the FEM is shown in Table 3.

Calculation of the life of the inner ring according to the L-P theory

Table 3

\begin{tabular}{|c|c|c|c|c|c|c|c|c|}
\hline Qmax & $2 b$ & lef & b & 20 & V & $\mathrm{N}$ & $\mathrm{N}$ & $\mathrm{N}$ \\
\hline $\mathrm{N}$ & $\mathrm{mm}$ & $\mathrm{mm}$ & MPa & $\mathrm{mm}$ & $\mathrm{mm} 3$ & cycles & mil. rev. & hours \\
\hline 356 & 0.158746 & 8.47 & 74 & 0.039686 & 51.81803 & $2.70 \mathrm{E}+10$ & $2.74 E+09$ & $9.12 \mathrm{E}$ \\
\hline 388 & 0.16325 & 8.75 & 79 & 0.040813 & 55.03566 & $1.64 \mathrm{E}+10$ & $1.66 \mathrm{E}+09$ & $5.53 \mathrm{E}+09$ \\
\hline 690 & 0.196973 & 10.14 & 114 & .049243 & 76.94489 & $6.08 \mathrm{E}+08$ & $6.15 \mathrm{E}+07$ & $2.05 E+08$ \\
\hline 2759 & 0.309751 & 13.15 & 277 & 0.077438 & 156.9132 & $2.35 \mathrm{E}+05$ & $2.38 \mathrm{E}+04$ & $7.92 \mathrm{E}+04$ \\
\hline 5721 & 0.393055 & 07 & 442 & 0.098264 & 213.1354 & $3.99 \mathrm{E}+03$ & $4.04 E+02$ & $1.35 E+03$ \\
\hline 8666 & 0.450145 & 14.31 & 577 & 0.112536 & 248.1074 & $4.01 E+02$ & $4.05 E+01$ & $1.35 E+02$ \\
\hline 11607 & 0.49522 & 14.44 & 695 & 0.123805 & 275.6014 & $7.96 \mathrm{E}+01$ & $8.05 E+00$ & $2.68 \mathrm{E}+01$ \\
\hline 565 & 33338 & 4.49 & 805 & 0.133334 & 297.7658 & $2.27 E+01$ & $2.30 \mathrm{E}+00$ & $7.67 E+C$ \\
\hline
\end{tabular}

Figure 8 shows the dependence of the service life of the inner ring of a taper roller bearing 32008 on the size of force of the maximum rolling element load calculated using the L-P theory. This dependence is used to calculate the life of a tapered roller bearing according to the maximum rolling element load, as it is the impact of preload that affects the size and distribution on the rolling elements according to the applied preload [10].

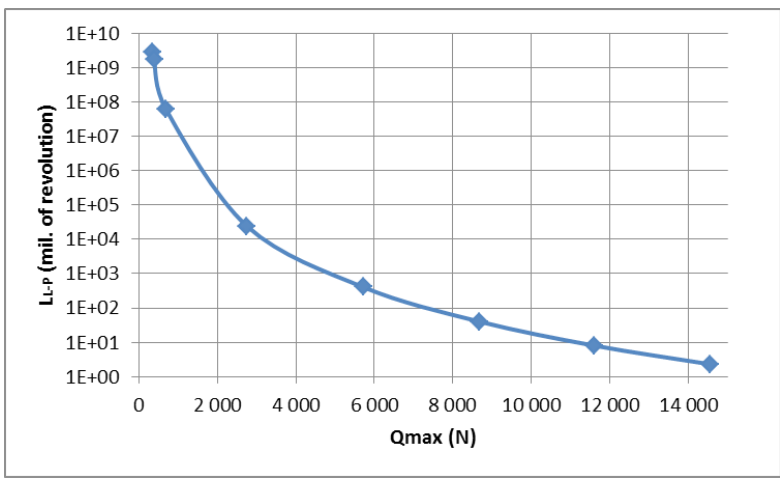

Fig. 8 Dependence of tapered roller bearing life on the maximum rolling element load

The analyzed values of the maximum rolling element load were used to calculate the values of the tapered roller bearing life for each working cycle at various preload values. Subsequently, using the ratio of required life (from the working cycle) and calculated life according to the L-P theory we determined the resulting life in hours (see Table 4 below).

Determination of optimal preload according to the L-P theory

Table 4

\begin{tabular}{|r|r|r|r|r|r|r|}
\cline { 2 - 7 } \multicolumn{1}{c|}{} & \multicolumn{1}{c|}{ preload (mm) } \\
\cline { 2 - 7 } \multicolumn{1}{c|}{} & \multicolumn{2}{|c|}{0} & 0.05 & \multicolumn{5}{c|}{0.1} & \multicolumn{3}{c|}{0.15} & \multicolumn{3}{|c|}{0.2} & 0.25 \\
\hline RArad (N) & Omax (N) & \multicolumn{5}{|c|}{} \\
\hline 56565.7 & 12868.7 & 12738.4 & 12614.3 & 12579.8 & 12753.5 & 13266.9 \\
\hline 47711.0 & 10798.8 & 10605.8 & 10484.3 & 10572.8 & 10957.1 & 11612.2 \\
\hline 33013.0 & 7414.5 & 7267.0 & 7291.2 & 7627.3 & 8299.9 & 9146.4 \\
\hline 25018.7 & 5600.7 & 5556.3 & 5733.9 & 6227.5 & 7024.8 & 7952.2 \\
\hline 15289.0 & 3418.9 & 3574.5 & 4009.2 & 4715.9 & 5634.7 & 6638.7 \\
\hline 12794.9 & 2864.2 & 3084.1 & 3597.3 & 4362.5 & 5306.9 & 6326.7 \\
\hline 11033.8 & 2473.6 & 2742.3 & 3313.8 & 4121.2 & 5082.5 & 6112.5 \\
\hline
\end{tabular}

\begin{tabular}{|c|c|c|c|c|c|c|}
\hline & \multicolumn{6}{|c|}{ preload $(\mathrm{mm})$} \\
\hline & 0 & 0.05 & 0.1 & 0.15 & 0.2 & 0.25 \\
\hline Arad (N) & \multicolumn{6}{|c|}{ LL-P (milion of revolution) } \\
\hline 56565.7 & 377 & 4.636 & 4.899 & 4.975 & 4.605 & 3.687 \\
\hline 47711.0 & 760 & .017 & 13.891 & 3.248 & 0.834 & 7.81 \\
\hline 33013.0 & .853 & 109.582 & 107.549 & 83.425 & 51.819 & 9.98 \\
\hline 25018.7 & 475.476 & 497.282 & 416.494 & 261.534 & 132.644 & 65.950 \\
\hline 15289.0 & 7673.72 & 5972.43 & 3127.771 & 1252.914 & .549 & $32.4 C$ \\
\hline 12794.9 & 20809.18 & 13715.84 & 5761.758 & 1943.529 & 344.148 & 239.243 \\
\hline 11033.8 & 47537.83 & 26591.70 & 9149.841 & 2678.003 & 821.707 & $290.4 \mathrm{C}$ \\
\hline & & & בכב. & & 60.0 & 156 \\
\hline
\end{tabular}

Figure 9 shows the dependence of the tapered roller bearing life on preload. Optimal preload was determined by calculation using finite-element analysis at $0.09 \mathrm{~mm}$. 

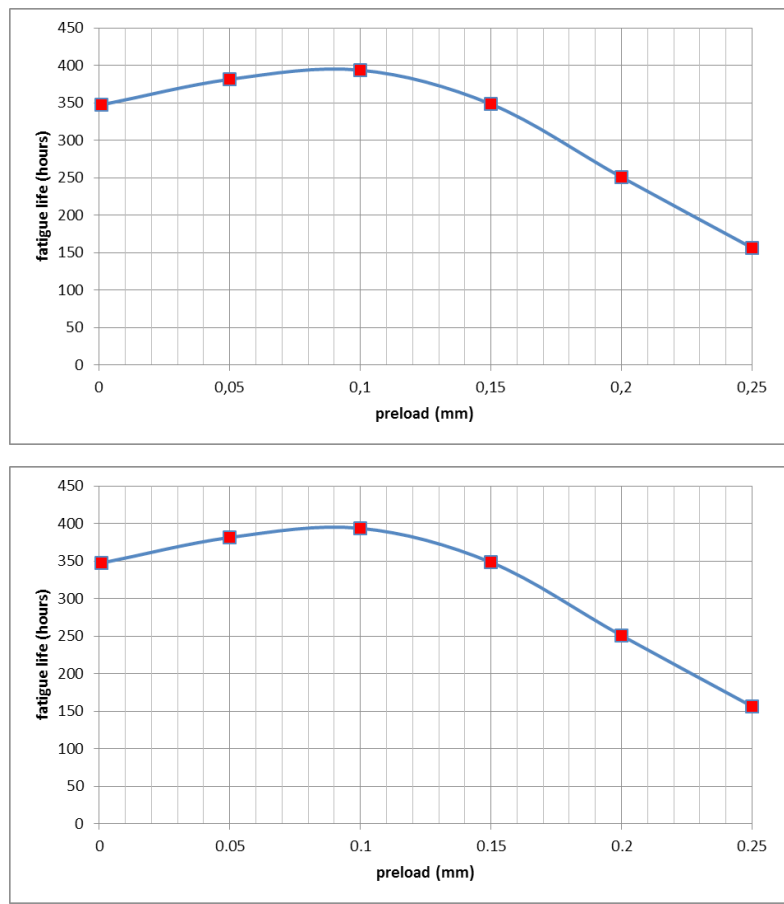

Fig. 9 Dependence of the bearing A life on preload

\section{Conclusion}

This paper shows the procedure that can be used to identify in an effective way the optimal preload with respect to the life of rolling bearings for a specific application defined by working cycle. The results of finite-element analysis showed its usefulness, and that analysis of contact and subsurface state of stress state and application of the Lundberg-Palmgren theory enable us to obtain a much more accurate estimate of the life of rolling bearings, compared to using the standard calculation method prescribed by ISO 281 .

Figure 10 shows the dependence of the calculated bearing A life on the size of preload in the fit of the output shaft by all the three procedures.

As can be seen, calculation of equivalent load using the method according to ISO 281 does not allow determination of optimal preload with respect to the life of bearings used in the shaft fit. A more accurate method of determining the optimal preload is analytical, by calculating the maximum rolling element load from radial load distribution using iteration procedure by Stribeck. However, this procedure enables to determine with some precision the maximum rolling element load only with purely radial load. Once the bearing load is contributed to also by outer axial component, the calculation of load distribution is difficult and may not give a reliable result. The most equitable result of the calculated rolling bearing life and determination of optimal preload can be achieved using the finite element method. Finite-element analysis enables to apply to the model of fit any outer load, take into account all design and technological impacts, analysis of contact and subsurface state of stress leads to obtaining the most accurate calculation of the life applying the Lundberg-Palmgren theory. With the today's powerful hardware and sophisticated software tools we can perform these analyses in an efficient manner that does not need to be too time-consuming.
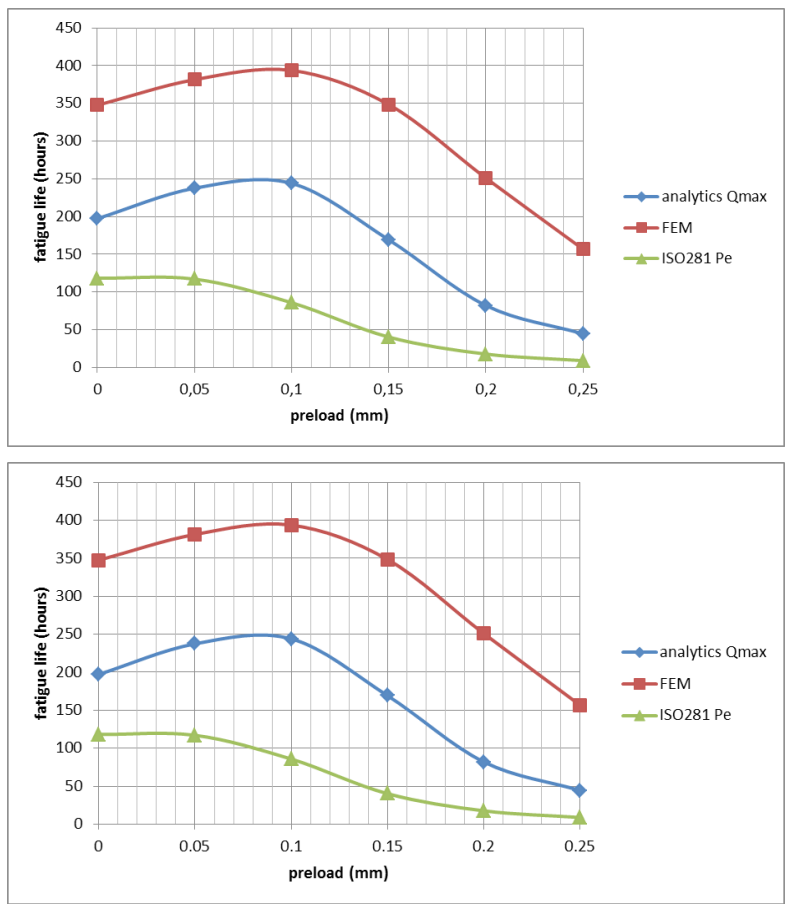

Fig. 10 Dependence of the bearing $A$ life on the size of preload calculated by various procedures

\section{Acknowledgements}

The research is supported by the following institutions with project Slovak Research and Development Agency under the contract No. APVV-0419-11 - Adaptation of modern computersimulation methods to the development of rolling bearings and their verification in real conditions.

The research is supported by the following institutions with project Slovak Research and Development Agency under the contract No. APVV-14-0508 - Development of new methods for the design of special large-size slewing rings.

The research is supported by the following institutions with project Scientific Grant Agency of the Ministry of Education, Science, Research and Sport of the Slovak Republic under the contract No. V-1/0396/14 - Research of the influence of construction and technological parameters of rolling bearings on the service life thereof.0, 


\section{COMMNICOIIONS}

\section{References}

[1] HARRIS, T. A., KOTZALAS, M. N.: Rolling Bearing Analysis, $5^{\text {th }}$ ed.: Essential Concepts of Bearing Technology, Taylor \& Francis, 2007, ISBN 0-8493-7183-X.

[2] HARRIS, T. A., KOTZALAS, M. N.: Rolling Bearing Analysis, $5^{\text {th }}$ ed.: Advanced Concepts of Bearing Technology, Taylor \& Francis, 2007, ISBN 0-8493-7182-1.

[3] BRANDLEIN, J., ESCHMANN, P., HASBARGER, L., WEIGARD, K.: Ball and Roller Bearings, Theory, Design and Application, $3^{\text {rd }}$ ed., John Wiley \& Sons, 1999. ISBN: 0471984526.

[4] SKF: Main Catalogue, SKF Group, 2007.

[5] Timken Products Catalogue, 2015.

[6] LEMAITRE, J., DESMORAT, R.: Engineering Damage Mechanics: Ductile, Creep, Fatigue and Brittle Failures, Springer, 2005, ISBN 3-540-21503-4

[7] ISO 281:2007 Rolling Bearings - Dynamic Load Ratings and Rating Life, Intern. Standards.

[8] OSWALD, F. B., ZARETSKY, E. V., POPLAWSKI, J. V.: Effect of Internal Clearance on Load Distribution and Life of Radially Loaded Ball and Roller Bearings, NASA/TM-2012-217115.

[9] SADEGHI, F., JALALAHMADI, B., SLACK, T. S., RAJE, N.: A Review of Rolling Contact Fatigue, J. of Tribology, 2009 , vol. 131/041403-1.

[10] DAMBAUGH, G. F.: Fatigue Considerations of High Strength Rolling Bearing Steels, 2006. 